\title{
Clinical Experience in Medical School
}

John Saultz, MD

(Fam Med. 2018;50(1):5-6.)

doi: 10.22454/FamMed.2018.601141

I $\mathrm{n}$ this issue of Family Medicine, we present a paper by Garcia-Rodriguez and colleagues from two medical schools in Alberta, Canada. In July 2015, these authors surveyed 146 incoming residents in two Canadian family medicine residencies about their medical school experiences with 69 clinical procedures. The authors used a core procedure list developed by the College of Family Physicians of Canada and the survey asked residents about their previous experience, level of confidence, and intention to include each procedure in their future practices. Two residencies were included, each with an urban and rural track. Ninety-one percent of these residents had attended a Canadian medical school and just over half had completed medical school in the province of Alberta. The study achieved a response rate of $82 \%$.

There was substantial variation in the medical school experiences of these residents, a variation all the more remarkable given the fact that over half of them were from just two schools. Their medical school experiences varied depending on their interest in rural practice. Residents planning a rural practice reported more experience with procedures and a greater interest in performing them in the future. There was no significant difference in the total number of procedures in which male and female residents reported confidence, but men were more likely to feel confident with wound care, emergency management, and resuscitation skills, while women were more confident with pap smears. Only 15 of the 69 procedures had been performed or observed more than five times by at least half of the residents. The study asked about student experience, but it did not assess the practice characteristics of their teachers. Previous work suggests that the scope of practice of family medicine preceptors has a major impact on student career choice. ${ }^{2,3}$ It seems obvious that this factor would also impact what students observe and learn to do.

What are the lessons to be learned from this paper? First, the variation among the students is remarkable, particularly when you consider that nearly all of them were from Canadian medical schools. The variation would probably be even greater in American family medicine residents because of the wider curricular diversity among American medical schools and the fact that American residencies include more graduates from osteopathic and international medical schools. Second, residency educators have long known that there are important gender differences in resident experience. It is now clear that this difference starts while learners are still in medical school. Finally, it is instructive to consider the third column in the paper's Table 2. This column lists the percent of students in the study who had never performed, assisted, or observed each procedure on the list. Over $40 \%$ of the students had never experienced a toenail removal, the removal of a foreign body from the ear or nose, anoscopy, thrombosed hemorrhoid drainage, aspiration or injection of a bursa, or peripheral venous access in an infant. On the other hand, over half of the students felt confident to independently perform some of the procedures. How much of the difference from student to student is explained by their own motivation and how much was determined by who their family medicine preceptor happened to be?

American medical schools are struggling with a critical shortage of preceptors willing 
to work with medical students on family medicine clerkships. Some institutions have tried to address this problem by increasing online education or by using simulation technology. Well-accepted standardized courses already exist for simulation of advanced cardiac life support (ACLS), obstetric procedures (ALSO), newborn life support (NRP), and advanced trauma care (ATLS), and standardized patients are commonly used to teach communication skills. But procedural skills are still learned largely by caring for actual patients. The clinical skills of a family physician are not abstract concepts to be learned only in theory; they are acquired and mastered by practice with real patients, side-by-side with teachers who exemplify the skills being taught. That is why medical school educators in family medicine need to be acutely concerned about the scope of practice of those they entrust with student clinical training. When experience with common procedures is not available in medical school, students require remediation in residency. This places a heavy burden on residency programs, and the challenge is further increased by restrictions in resident work hours and by a declining number of role models in full-scope practice after residency. ${ }^{4}$

We know that insufficient clinical experience in medical school is a problem; maybe it is time to do something about it. Consider what might happen if family medicine residency directors developed a way to explicitly rank medical schools based on how well prepared their graduates are to enter a residency in our discipline and then publically reported the results. We already rank medical schools accordingly to the quantity of family medicine graduates they produce. ${ }^{5,6}$ It would not be that difficult to assess entering residents and produce a ranking of schools based on quality as well. First-year residents already take the in-training exam from the American Board of Family Medicine as a measure of knowledge. In this issue, Garcia-Rodriguez and colleagues have shown us one way to assess procedural experience. All we would need to add would be assessments of behavioral skills and professionalism. Medical school leaders clearly take notice of their schools' ranking in research productivity and in the annual ranking of their academic reputations by US News and World Report. It is time to give credit to schools that consistently provide excellent clinical experience for their students and to call out those that do not. Medical schools are not shy about charging as much tuition as the market will bear and enrolling more students each year in spite of the preceptor shortage. Perhaps the residency education community should be more demanding about the product they produce.

\section{References}

1. Garcia-Rodriguez JA, Dickinson JA, Perez G, Ross D, Au L, Ross S, Babenko O, Johnston I. Procedural knowledge and skills of residents entering Canadian family medicine programs in Alberta. Fam Med 2018;50(1):10-21.

2. Anthony D, White J, Margo K, Tarn DM. Scope of practice and family medicine match rates: results from a CERA clerkship directors' survey. Fam Med. 2017;49(3):177-182.

3. Saultz J. Taking responsibility for family medicine student interest. Fam Med. 2017;49(3):173-174.

4. Coutinho AJ, Cochrane A, Stelter K, Phillips RL Jr, Peterson LE. Comparison of intended scope of practice for family medicine residents with reported scope of practice among practicing family physicians. JAMA. 2015;314(22):2364-2372.

5. Kozakowski SM, Travis A, Marcinek JP, Bentley A, Fetter GT Jr. Results of the 2017 National Resident Matching Program and the American Osteopathic Association Intern/Resident Registration Program. Fam Med. 2017;49(9):679-685.

6. Kozakowski SM, Travis A, Marcinek JP, Bentley A, Fetter GT Jr. Entry of US medical school graduates into family medicine residencies: 2016-2017. Fam Med. 2017;49(9):686692. 